\title{
Comportamento do consumidor: fatores que influenciam o consumo virtual nas redes sociais
}

\section{Consumer behavior: factors affecting the virtual consumption in social networks}

\author{
Daniele Nespolo ${ }^{1}$ \\ Deise Taiana de Ávila Dias ${ }^{2}$ \\ Paula Patrícia Ganzer ${ }^{3}$ \\ Cristine Hermann Nodari ${ }^{4}$ \\ Milene Vieira Figueira ${ }^{5}$ \\ Maria Emilia Camargo ${ }^{6}$
}

1 Doutoranda em Administração da Universidade de Caxias do Sul Mestre em Administração pela Universidade de Caxias do Sul (2014). Possui graduação em Ciências Contábeis pela Universidade de Caxias do Sul (2009) e MBA em Gestão Empresarial pela Universidade do Vale do Rio dos Sinos (2011). E-mail: nespolo.daniele@gmail.com

2 Cursando Mestrado em Administração pela Universidade de Caxias do Sul, Rio Grande do Sul Brasil. Bolsista CAPES. Possui graduação em Administração pela Faculdade da Serra Gaúcha - Gestão de Negócios (2012). E-mail: deiset.dias@gmail.com

3 Doutorando em Administração pela Pontifícia Universidade Católica do Rio Grande do Sul, PUCRS, Brasil e pela Universidade de Caxias do Sul, UCS, Brasil. Mestrado em Administração pela Universidade de Caxias do Sul, UCS, Brasil. E-mail: ganzer.paula@gmail.com

4 Pós-doutorado. Bolsista do Programa Nacional de Pós-Doutorado da Coordenação de Aperfeiçoamento de Pessoal de Nível Superior (PNPD/CAPES). Doutora em Administração pela Pontifícia Universidade Católica do Rio Grande do Sul (PUCRS), Brasil e pela Universidade de Caxias do Sul (UCS) Brasil. Mestra em Administração pela Universidade de Caxias do Sul (UCS), Brasil. Especialista em Gestão Empresarial pela Fundação Getúlio Vargas (FGV) Brasil. Possui experiência gerencial em multinacional. Principais temas de interesse e linhas de pesquisa: Gestão da Inovação, Competitividade e Mercado. Atualmente, é professora do Mestrado Acadêmico em Administração da Universidade Potiguar. E-mail: cristine.nodari@ gmail.com

5 Graduação em Matemática Aplicada e Computacional pela Universidade Federal do Rio Grande do Sul (1994) e mestrado em Engenharia Mecânica pela Universidade Federal do Rio Grande do Sul (2000). Atualmente, é professora na Universidade de Caxias do Sul. E-mail: mvfigueira@ ucs.br

$6 \quad$ Licenciatura em Estatística pela Universidade Federal de Santa Maria (1977). Licenciatura em Administração e Controle pela Universidade Federal de Santa Maria (1977). Bacharelado em Ciências Administrativas pela Universidade Federal de Santa Maria (1975). Bacharelado em Ciências Econômicas pela Universidade Federal de Santa Maria (1979). Graduação em Licenciatura em Economia e Mercado pela Universidade Federal de Santa Maria (1977). Mestrado em Engenharia de Produção pela Universidade Federal de Santa Maria (1979). Doutorado em Engenharia de Produção pela Universidade Federal de Santa Catarina (1992). Pós-doutorado em Controle Estatístico de Processo pela Universidade Estatal Técnica de Kazan. Pós-doutorado em Métodos Quantitativos Aplicados à Gestão pela Universidade do Algarve Portugal. E-mail: kamargo@terra.com.br 


\section{Resumo}

O estudo teve como objetivo geral identificar os fatores determinantes na decisão de compra dos consumidores virtuais da loja Treko's Mania, empresa de pequeno porte, do segmento de bazar. Destacam-se os objetivos específicos, os quais buscam identificar o perfil dos consumidores que compram por meio da fanpage Treko's Mania, identificar as vantagens e as dificuldades elencadas pelos consumidores referentes à compra virtual. Desenvolveu-se uma pesquisa de natureza aplicada, com abordagem quantitativa e objetivo exploratório, utilizando como procedimentos metodológicos a pesquisa bibliográfica e o levantamento de dados, com questionário estruturado baseado na Escala de Likert. $\mathrm{Na}$ análise dos dados, com utilização do software IBM SPSS Statistics 20, aplicou-se estatística descritiva e correlação simples. Os resultados afirmaram que os seguintes critérios influenciam a decisão de compra dos clientes da fanpage Treko's Mania: recebimento de produtos no prazo fornecido, bom relacionamento, variedade de produtos, condições de pagamento e recebimento dos produtos conforme descritos.

Palavras-chave: Marketing de relacionamento. Comportamento do consumidor virtual. Redes sociais.

\section{Abstract}

The study had as main objective to identify the determining factors in the purchasing decision of virtual consumers store Treko's Mania, a small business, the bazaar segment. The specific objectives, which seek to identify the profile of consumers who shop through the Fan page Treko's Mania, identify the advantages and the difficulties listed by consumers for the virtual purchase. It was developed a research of an applied nature, with a quantitative approach and exploratory objective, and the methodological procedures bibliographic research and data collection, with structured questionnaire based on the Likert scale. In data analysis, using IBM SPSS Statistics 20 software was applied to descriptive statistics and simple correlation. The results stated that the following criteria influence the purchase decision of the customer's Fan page Treko's Mania: receiving products on time provided, good relationship, product variety, conditions of payment and receipt of the products as described.

Keywords: Relationship marketing. Consumer behavior virtual. Social networking.

\section{Introdução}

Com a globalização e os avanços da internet, s redes sociais vêm desempenhando uma função importante no marketing de 
relacionamento, no que tange à organização e ao consumidor. Nesse sentido, surgem as oportunidades de negócios on-line via fanpages do Facebook, possibilitando a microempreendedora em estudo administrar sua empresa, expor seus produtos e o atendimento full time aos seus clientes.

Uma vez que Lipovetisky (2007) diz que uma nova realidade está sendo delineada, a qual vem modificando a sociedade de consumo para uma representação simbólica de ordem econômica e da história cotidiana da sociedade moderna, o que justifica a extensão com que está sendo conduzido o consumo pela sociedade contemporânea. Corroborando, Bauman (2008) afirma que o consumo pode ser visto como algo estável e irremovível, sem limites, seja de caráter temporal ou espacial, ou seja, ele está intrínseco às condições humanas.

A organização investigada foi a loja Treko's Mania, fundada em 23 de fevereiro de 2013, localizada na cidade de Bento GonçalvesRS. Atualmente, esta empresa possui uma loja virtual, e faz da rede social Facebook a sua principal ferramenta de trabalho. Até o momento da realização do estudo, seus principais clientes eram pessoas físicas, residentes na Serra Gaúcha. Uma das metas da empresa é ter oportunidade de expansão dos seus negócios não só no Rio Grande do Sul, como em todo Brasil.

A questão de pesquisa então é: quais os fatores determinantes na decisão de compra dos consumidos virtuais do estudo de caso? Este estudo tem como objetivo geral identificar os fatores determinantes na decisão de compra dos consumidores virtuais da loja Treko's Mania. Os objetivos específicos, que sustentam o objetivo geral, buscam: (1) identificar o perfil dos consumidores que compram por meio da fanpage Treko's Mania; e (2) identificar as vantagens e as dificuldades elencadas pelos consumidores referentes à compra por meio da fanpage da loja Treko's Mania.

A coleta dos dados, primeiramente ocorreu por intermédio de uma pesquisa qualitativa exploratória, por meio de uma entrevista em profundidade com os proprietários da empresa. Posteriormente, ocorreu 
a pesquisa quantitativa descritiva com aplicação dos questionários fechados para 76 clientes da loja Treko's Mania, uma representação de $34,70 \%$ da população.

A utilização do software IBM SPSS Statistics 20 proporcionou a análise e interpretação dos dados por meio dos resultados de estatísticas descritivas e correlação simples.

A teoria do comportamento do consumidor em compras virtuais vem se desenvolvendo e o presente estudo de caso visa contribuir com este estudo teórico empírico neste tema, podendo ainda ser útil para a gestão da loja estudo de caso, bem com de concorrentes.

\section{Referencial teórico}

\subsection{Marketing de relacionamento}

O princípio do marketing relacional "consiste em manter uma base de clientes rentáveis e fiéis” (BRAMBILLA, 2008, p. 110). Nas últimas décadas, o mercado vem passando por constantes mutações, sendo assim, as organizações buscam se adequar às novas necessidades e exigências dos consumidores. Dentre essas adaptações, está o atendimento ao comprador de maneira personalizada, bem como a troca relacional, não considerando somente mais uma venda, uma simples transação comercial. Nesse contexto, surge a oportunidade de desvendar as preferências, os gostos e as necessidades destes consumidores, objetivando satisfazê-los com produtos e/ou serviços de qualidade, atendimento exclusivo, preços competitivos, entre valores considerados pelos clientes, assim, emerge o marketing de relacionamento.

Corroborando, Grönroos (1994) define marketing de relacionamento em um contexto processual, o qual consiste em um processo de identificar e estabelecer, manter, aumentar e, se necessário, encerrar os relacionamentos com consumidores e outros stakeholders, com lucro, para que as finalidades de todas as partes abrangidas sejam obtidas, em que isto se considera por uma doação mútua e também 
pelo cumprimento das promessas. Essas atitudes demandam tempo e dedicação total, porém tendem criar laços entre as empresas e seus consumidores, difíceis de serem desfeitos.

Nesse contexto, Brambilla (2009) ressalta que, em longo prazo, o marketing de relacionamento pode resultar em vantagens competitivas, tendo como premissa a sustentação de relações satisfatórias com seus consumidores, demonstrando confiabilidade e compromisso, precedendo na fidelização dos mesmos. Na busca pela fidelização de clientes, há necessidade de aprimorar a comunicação, objetivando compreender como as experiências o fazem reagir e de que maneira elas influenciam no seu comportamento, no que tange à manutenção da fidelidade.

No ponto de vista de Parvatiyar e Sheth (2000), o marketing de relacionamento abrange um processo ininterrupto de atividades de cooperação, a fim de criar ou adicionar o valor econômico mútuo a um custo menor. Com base nessa visão dos autores, fica compreensível a necessidade de modificação nas estratégias de marketing para diferentes conceitos, em que seja relevante a manutenção de relações sólidas e duradouras, para o desenvolvimento do negócio, sua sustentabilidade e, por conseguinte, a concepção de vantagens competitivas sustentáveis.

\subsection{Comportamento do consumidor virtual}

Para que o marketing de relacionamento aconteça, faz-se necessário entender o comportamento do consumidor. Desse modo, Kotler (2006) define o comportamento do consumidor como cada indivíduo se comporta diante de um determinado produto e/ou serviço a ser obtido eou consumido, com o intuito de atender suas necessidades, seja reais ou emocionais. O comportamento do consumidor é caracterizado pelas atividades mentais e emocionais consolidadas na seleção, aquisição e uso de produtos e/ou serviços para a satisfação de necessidades e desejos. Os autores Churchill Júnior e Peter (2000) corroboram afirmando que o desempenho do cliente é percebido como: o estudo dos métodos abrangidos quando os compradores selecionam, adquirem, utilizam, 
dispõem de produtos, serviços, opiniões ou expectativas para satisfazer suas necessidades e pretensões.

Mediante entendimento de Sheth, Mittal e Newman (2001, p. 29) "o comportamento do cliente são as atividades físicas e mentais realizadas por clientes de bens de consumo e industriais que resultam em decisões e ações". No momento da compra, o consumidor os objetiva por fazer sua melhor escolha, diminuir o esforço em sua tomada de decisão, minimizar os sentimentos negativos, e maximizar a disposição de explicar a sua escolha (ENGEL; BLACKWELL; MINIARD, 2005).

Já na visão de Hawkins, Mothersbaugh e Best (2007), o comportamento do consumidor abrange o estudo de indivíduo, grupos ou organizações e o processo que eles usam para selecionar, adquirir, usufruir e descartar de produtos e/ou serviços, para atender as necessidades e o impacto que esses processos têm sobre o comprador e a sociedade. Portanto, entender o comportamento do consumidor é um bom negócio, uma vez que as organizações existem para satisfazer as necessidades dos seus clientes.

Com base na opinião de Anandarajan et al. (2006), com a chegada da internet, gerou a possibilidade para seus usuários de ampliar e aprimorar a velocidade em suas transações encurtou distâncias entre organizações e clientes, possibilitando distintas opções de canais de compra, as quais estão dispostas a suprir os desejos e necessidades dos consumidores. Por outro lado, tais desejos e necessidades só podem ser atendidos na medida em que os profissionais de marketing obtêm a compreensão das pessoas ou empresas que consumirão os produtos e/ ou serviços que eles estão tentando comercializar e que fazem melhor do que seus concorrentes (SOLOMON, 2008).

Xavier (2012) escreve que a internet vem provocando significativas transformações na maneira como os indivíduos se comunicam, trabalham, buscam informações e adquirem produtos. A venda via internet tem crescido de forma contínua, alterando parcialmente o perfil do consumidor. Com o seu crescente acesso, os compradores virtuais passaram a ter mais poder de comunicação, o que lhes permite obter 
e trocar informações, promovendo e interferindo no seu processo de compra.

\subsection{Redes sociais}

Atualmente, algumas empresas estão utilizando as redes sociais para melhor relacionarem-se com seus clientes, ampliando seus relacionamentos e entendendo como está o comportamento do seu público-alvo. É nesse contexto, que Castells (1999) afirma que as redes são como um conjunto de amarrações, ou seja, cada nó desta conexão pode ser representado como uma pessoa ou um grupo de pessoas, assim o que ela representa depende consequentemente do tipo de rede na qual é pertencente. As ligações entre esses nós estão incorporadas onde anteriormente havia somente ações lineares (SODRÉ, 2002).

Por outro lado, Capra (2002) diz que no cenário atual, com o mercado atrelado à era da informação, as atividades sociais estão sendo instituídas cada vez mais no circuito das redes, acarretando um fenômeno social que tem influência significativa no poder da crítica e da atitude. As redes sociais, na visão de Marteleto (2001), são formadas por um grupo de indivíduos que unem ideias e recursos, tendo valores e interesses que em comum. Essa afinidade originada pelas redes sociais consente aos usuários o compartilhamento entre si, seja de informações ou conhecimentos adquiridos com experiências anteriores, com o passar do tempo resulta no fortalecendo a rede a qual fazem parte.

Não obstante, Costa et al. (2003, p. 73) afirmam que a rede "é uma forma de organização caracterizada fundamentalmente pela sua horizontalidade, isto é, pelo modo de inter-relacionar os elementos sem hierarquia". Destarte, as redes sociais são sites composto por pessoas, denominados membros, onde participam, expressam, discutem e expõem seus assuntos particulares e profissionais, assim como seus desejos, sonhos e pretensões (SCHULTZ, 2007).

A expansão da internet resultou em uma nova maneira de dar cumprimento às atividades de consumo (HUANG; BEHARA, 2007; 
DEARSTYNE, 2007), a saber, que os consumidores têm ágil acesso à informação e às ofertas, os quais podem utilizar as redes sociais para tomar conhecimento de produtos, organizações, a realização de compras, além de compartilhar conhecimentos e experiências de consumo com outros usuários. Assim, os autores Besanko et al. (2012) afirmam, quando os compradores conferem maior valor a determinado produto e/ou serviço em função da sua utilização por outros consumidores, é chamado efeito de rede.

Na visão dos autores Cortimiglia, Ghezzi e Renga (2011), dentre as redes sociais líderes de mercado de serviços estão o Facebook e YouTube, os quais já consolidaram a versão móvel de suas propriedades de web e estão obtendo os resultados positivos. No entanto, ainda existem uma série de questões não resolvidas sobre os modelos de negócios das tecnologias sociais convergentes, principalmente para os serviços que não desfrutam dos benefícios de liderança de mercado que as gigantes mencionadas possuem.

\subsubsection{Rede social Facebook}

Para melhor interação entre organização e clientes, um dos meios que vêm sendo utilizado é a rede social on-line Facebook, porquanto, nos últimos anos ela vem apresentando um crescimento exponencial no número de membros. Para Acquisti e Gross (2006), o objetivo das redes sociais é oferecer meios atrativos para interação, comunicação e negócios. Uma vez que, permite aos seus usuários criar um perfil público de uma pessoa física, pessoa jurídica, marca e até mesmo de personagens. Por intermédio dos perfis em redes sociais é possível ageração de informações, sejam foto, vídeo ou mídia digital de qualquer natureza, e a oportunidade do compartilhamento das mesmas com os demais usuários da rede (OVASKA; LEINO, 2008).

Recuero (2009) diz que os sites de redes sociais são uma consequência da apropriação dos instrumentos de comunicação interceptada por um computador e pelos seus atores sociais. Os quais apresentam a possibilidade de construção de perfis públicos e viabilizam 
o desenvolvimento de interações nestes sistemas. Dessa forma, é crescente o número de organizações que vêm utilizando as redes sociais para divulgação dos seus produtos e/ou serviços, marca e promoções.

Por meio da rede social Facebook é possível a criação de páginas corporativas, onde as organizações utilizam para divulgar e compartilhar novidades, eventos e outras ações de publicidade e marketing. Conforme explicitado na fanpage da própria rede social Facebook, "a missão do Facebook é dar às pessoas o poder de compartilhar e tornar o mundo mais aberto e conectado" (site Facebook, 2013).

\subsubsection{Fanpages}

As páginas corporativas da rede social Facebook são chamadas de fanpages, as quais objetivam a divulgação das organizações, produtos, serviços, profissionais, dentre outros. Para defini-las, cita-se a definição direcionada pela homepage do Facebook (2013):

As páginas de fãs (fanpages) existem para que as organizações, empresas, celebridades e bandas transmitam muitas informações aos seus seguidores ou ao público que escolher se conectar a elas. Semelhante aos perfis, as Páginas podem ser aprimoradas com aplicativos que ajudem as entidades a se comunicarem e interagirem com o seu público e adquirirem novos usuários por recomendações de amigos, históricos dos feeds de notícias, eventos do Facebook e muito mais.

Autilização de fanpages possibilitaqueas organizações identifiquem oportunidades, desafios e coordenem respostas apropriadas, com agilidade. A rede social Facebook está sendo eleita pelos empresários, uma vez que podem fazer a divulgação dos seus produtos e/ou serviços com custo baixo, e de uma maneira que tendem alcançar um público maior, do que outras formas oferecidas pelo mercado. Sabendo-se que a sociedade costuma agrupar-se com seus semelhantes conforme seus interesses comuns. 
Dambrós e Reis (2008) explicam que as redes sociais também podem ser chamadas de redes de relacionamentos sociais, pois é um processo de interação entre consumidores e empresas. Os clientes têm a oportunidade de demonstrarem envolvimento e colaboração, o qual resultará em debates entre os próprios usuários. Sendo assim, a criação e a gestão de fanpages possibilitam vantagens para as organizações que as utilizam. Em especial, no que tange a aproximação do seu público alvo, possibilitando o selamento dos laços relacionais, permitindo maior contato e apoiando no processo de conhecimento de necessidades e expectativas dos consumidores.

Com a utilização da fanpage Facebook, o fornecedor pode divulgar seus produtos, interagir com o cliente e realizar promoções exclusivas para os seus fãs (pessoas que utilizam a ferramenta curtir, específica desta rede social), esse é um dos motivos pelos quais desperta nos consumidores, o interesse em tornarem-se fãs da organização. Por outro lado, oportuniza à empresa aumentar a capacidade de divulgação de sua marca e seus produtos e/ou serviços.

\section{Metodologia da pesquisa}

\subsection{Ambiência da pesquisa}

A empresa estudada foi a Treko's Mania, fundada em 23 de fevereiro de 2013, localizada na cidade de Bento Gonçalves, no Rio Grande do Sul (RS). Esta organização possui uma loja virtual, dando início às suas atividades por meio da rede social Facebook. São comercializados produtos de origem chinesa e americana, oferecendo atualmente aproximadamente 250 produtos, dentre eles são: bolsas, cintos, canecas, cases para celulares, películas para celulares, roupas femininas e masculinas, mouses, óculos, pen drives, caixas de sons, relógios, dentre outros.

A organização não possui funcionários, contando com seus proprietários, profissionais que estão em constante qualificação e especialização para melhor atender seus clientes. Após sua fundação, 
em menos de cinco meses de atividades, chegou-se a mais de 1500 pessoas curtindo a fanpage. Desde então, o trabalho da Treko's Mania passou a ser reconhecido não só pelos clientes residentes em Bento Gonçalves, como em outras cidades da região: Caxias do Sul, Farroupilha, Garibaldi, Carlos Barbosa, Veranópolis e Bom Princípio.

\subsection{Técnicas e procedimentos de pesquisa}

Esta investigação realizou-se em duas fases, sendo que a primeira foi de cunho qualitativo-exploratório e, a segunda, de cunho quantitativo-descritivo (MALHOTRA, 2010). Na pesquisa exploratória, aplicou-se a entrevista em profundidade, a qual foi gravada, tendo duração de aproximadamente uma hora, a fim de buscar subsídios para conhecer o funcionamento e o processo de venda de uma loja virtual. Já na pesquisa descritiva, com auxílio do software IBM SPSS Statistics 20, buscou-se entender o comportamento destes consumidores virtuais e o quanto cada critério avaliado pode interferir na sua decisão de compra.

A fase quantitativa, de caráter descritivo, utilizou um questionário estruturado para a coleta dos dados, validado por um expert da área. Malhotra (2010) destaca que o questionário é uma técnica estruturada para coleta de informações, que incide em uma série de determinadas perguntas escritas. A fase quantitativa exploratória foi realizada entre os dias 29 de agosto a 12 de setembro de 2013. O instrumento de coleta dos dados continha 26 questões fechadas, sendo que as questões de número 1 a 9 tinham o propósito de identificar perfil socioeconômico dos respondentes, e as afirmações de 10 a 26 foram utilizadas para identificar o comportamento destes consumidores.

Por conseguinte, para as afirmações de 10 a 26 utilizou-se a Escala Likert com cinco pontos, a qual apoia pesquisas em que se solicita que os entrevistados apontem um grau de concordância ou discordância referente a cada uma das afirmações. Caracteristicamente, cada item da linha graduada tem cinco categorias de respostas, que vão desde "discordo totalmente" até "concordo totalmente". 
Tabela 1 - Pontuação da Escala Likert e seus significados

\begin{tabular}{l|l}
\hline Pontuação da Escala Likert & Significado da pontuação \\
\hline 1 & Discordo totalmente \\
\hline 2 & Discordo parcialmente \\
\hline 3 & Indiferente \\
\hline 4 & Concordo parcialmente \\
\hline 5 & Concordo totalmente \\
\hline
\end{tabular}

Fonte: Elaborada pelas autoras (2013).

O instrumento de coleta dos dados, elaborado no Google Docs, foi disponibilizado na fanpage da loja Treko's Mania de 29 de agosto a 12 de setembro de 2013, para que seus 219 clientes com cadastro de compra ativo pudessem colaborar no desenvolvimento desta investigação. Foram obtidas 76 respostas, ou seja, uma taxa de retorno de $34,70 \%$ da população.

Ao final, realizou-se a correlação simples entre todos os critérios estudados, utilizando-se do mesmo software para a análise e interpretação dos resultados. Com este resultado, pode-se identificar quais são os critérios que refletem significativa importância no momento da decisão de compra do cliente, se existe relação entre eles e o grau em que suas variações estão relacionadas (MALHOTRA, 2010).

\section{Resultados e discussão}

Na pesquisa qualitativa-exploratória pôde-se conhecer a história inicial da empresa. Os proprietários costumavam adquirir produtos importados por compra online (via sites) somente para uso pessoal, e a pedido de alguns amigos, começaram a intermediar compras para terceiros, sem objetivo de negócio em longo prazo. Com o passar do tempo os pedidos foram aumentando, e outras pessoas passaram a solicitar essa intermediação para adquirir produtos, foi então que surgiu a ideia de criar uma loja virtual via fanpage no Facebook 
Inicialmente, começaram com apenas um produto, cases para celulares, sendo que não disponibilizavam deste produto para pronta entrega, sua comercialização era somente por encomenda. No decorrer do seu negócio, os próprios consumidores começaram sugerir outros produtos e solicitavam que tivessem um estoque, uma vez que reduziria o tempo da entrega. Atualmente, a empresa recebe em média 15 a 20 pedidos diariamente, conta com estoque próprio e os produtos que não disponibiliza se dispõe a entregá-los por encomenda.

Para a decisão de compra, alguns clientes expõem a necessidade de conhecer os produtos presencialmente, antes de efetuar o pedido. Analisando essas constantes solicitações, e na demonstração de confiabilidade ao consumidor, a empresa deu inicio às atividades para dispor de um showroom de todos os seus produtos. Assim, os clientes poderão ter a oportunidade de conhecer as funcionalidades e ainda prová-los, quando for o caso, contam os entrevistados. A previsão para funcionamento do showroom é até dezembro de 2013.

Na fanpage da Treko's Mania os produtos são expostos, seguidos de uma prévia descrição. O consumidor efetua o pagamento da sua compra por depósito bancário ou cartão de crédito, onde consegue parcelar em até sete vezes. No cálculo final do produto é descrito o valor do frete e acréscimo quando parcelado, também lhe é informado o prazo para recebimento do produto. Prezando pela satisfação total dos seus clientes, caso o comprador não fique satisfeito com o produto recebido, avaliando a situação, tem a possibilidade da devolução do produto e de reaver seu dinheiro.

A amostra analisada é composta de 76 clientes ativos da fanpage Treko's Mania, em sua maioria com idade entre 21 e 30 anos $(43,4 \%)$, do sexo feminino $(93,4 \%)$ e residentes em Bento Gonçalves (55,3\%). Quanto ao estado civil, as alternativas disponíveis no questionário eram iguais às categorias apresentadas na rede social Facebook. Os respondentes solteiros e aqueles em um relacionamento sério, apresentaram igual representatividade $(31,6 \%)$. O nível de escolaridade predominante entre a amostra foi o ensino superior incompleto $(48,7 \%)$, e a grande maioria 
apresenta trabalho remunerado $(88,2 \%)$ e possui renda familiar mensal entre $R \$ 3.500,00$ e $R \$ 4.200,00(21,1 \%)$.

A partir dos resultados obtidos, identificou-se que 30,3\% da amostra adquire produtos uma vez por mês pela fanpage da Treko's Mania, seguido de $22,4 \%$ que adquirem a cada dois meses e de $22,4 \%$ que adquirem a cada três meses. Apenas 2,6\% dos respondentes adquirem produtos semanalmente na fanpage. Quanto ao prazo de entrega dos produtos, $97,4 \%$ dos respondentes o consideram satisfatório, e $86,8 \%$ afirmam que os produtos são recebidos dentro do prazo estipulado pela empresa.

Dando início ao levantamento dos fatores que influenciam na decisão de compra, $75 \%$ dos respondentes afirmaram que concordam totalmente que a qualidade é um dos fatores determinantes para concretização das suas compras via fanpage Treko's Mania, e apenas $1,3 \%$ respondeu que discorda parcialmente desta afirmação.

Quando questionados sobre o atendimento, 89,5\% dos respondentes consideraram que a loja possui um bom atendimento, dentro das suas expectativas, e 2,6\% foram indiferentes quanto a esse aspecto (vide Figura 1).

Figura 1 - Atendimento

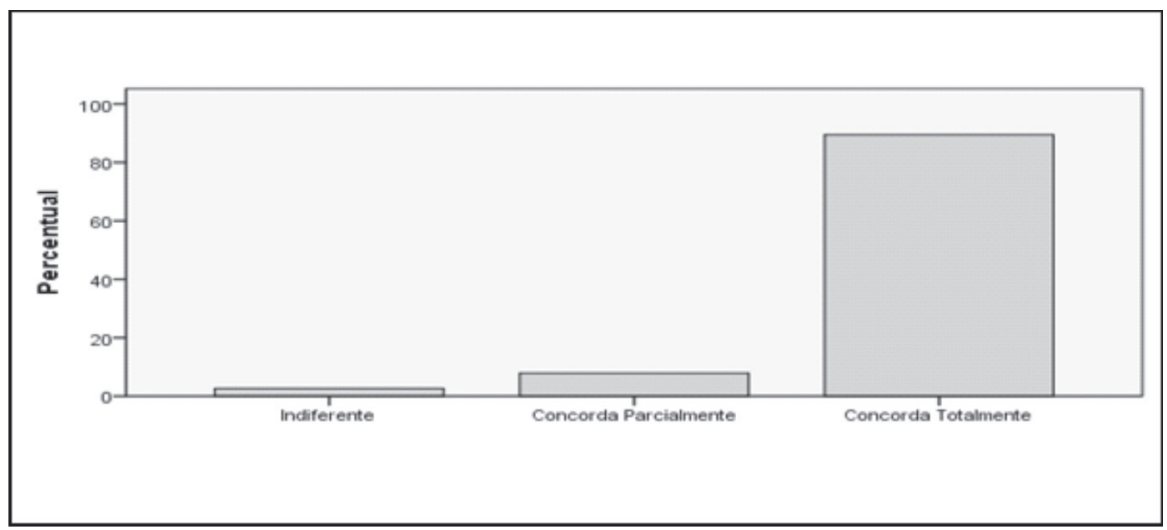

Fonte: Elaborada pelas autoras por meio do software IBM SPSS Statistics (2013). 
Com relação aos preços das mercadorias, 48,7\% da amostra concorda totalmente que os preços praticados pela loja estão de acordo com as demais fanpages, e 1,3\% discorda totalmente dessa afirmação.

Em se tratando de condições de pagamento, 65,8\% dos respondentes concordam totalmente que a loja possui condições de pagamento facilitadas, e estão de acordo com suas expectativas, 1,3\% discorda parcialmente e 1,3\% discorda totalmente dessa afirmação.

Figura 2 - Condições de pagamento

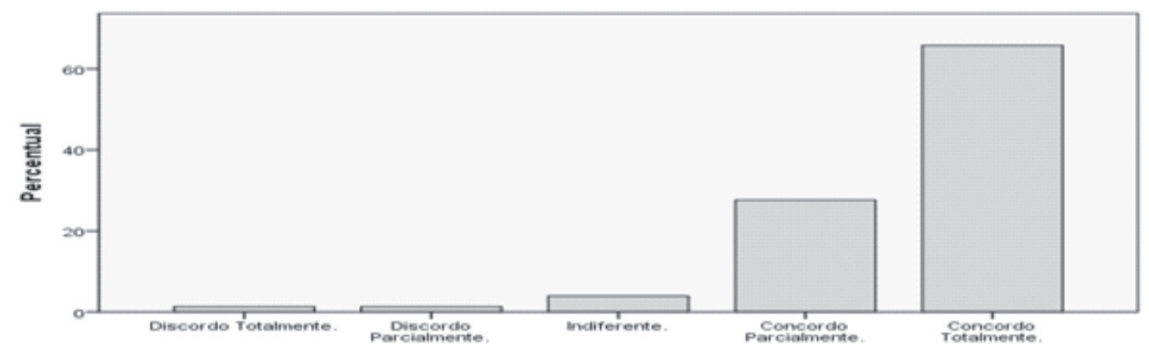

Fonte: Elaborada pelas autoras por meio do software IBM SPSS Statistics (2013).

Quando questionados sobre a comunicação com a Treko's Mania, 93,4\% dos respondentes concordam totalmente que quando há necessidade de comunicação com a loja, o atendimento é rápido e seus problemas são resolvidos em todas as ocasiões, e 6,6\% responderam que concordam parcialmente. Não houve respostas que discordam parcial ou totalmente dessa afirmação (vide Figura 3). 
Figura 3 - Comunicação com a Treko's Mania

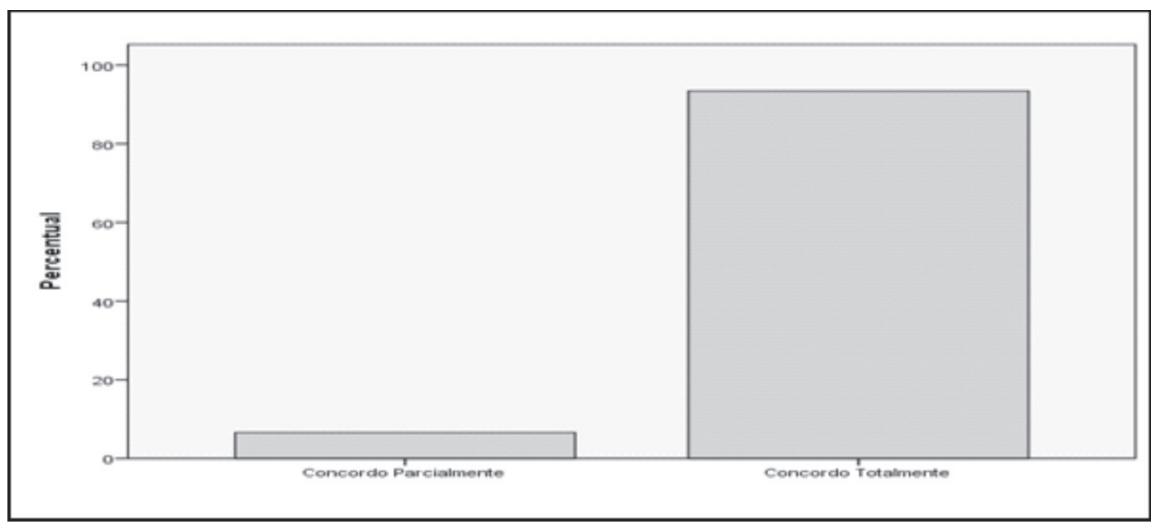

Fonte: Elaborada pelas autoras por meio do software IBM SPSS Statistics (2013)

Quanto ao relacionamento, $94,7 \%$ dos respondentes afirmaram que, mesmo sendo via internet, a Treko's Mania mantém bom relacionamento com seus clientes; $2,6 \%$ concordam parcialmente com essa afirmação e 2,6\% foram indiferentes a esse critério.

Figura 4 - Bom relacionamento

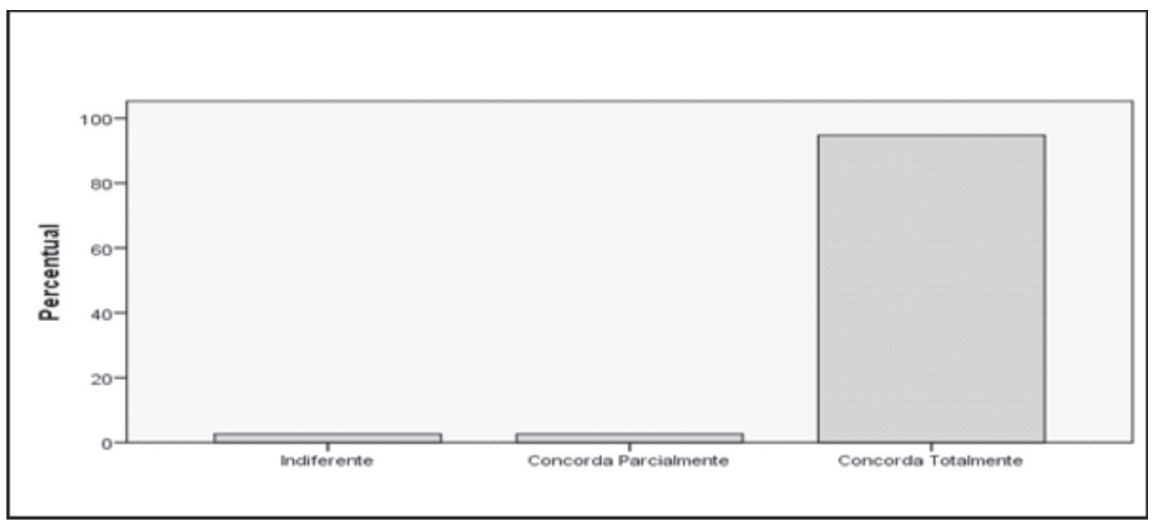

Fonte: Elaborada pelas autoras por meio do software IBM SPSS Statistics (2013).

Quando questionados quanto à pratica de pós-venda, relacionada à preocupação da loja virtual com a sua satisfação ou insatisfação 
na compra, $67,1 \%$ da amostra concordou totalmente, e apenas $1,3 \%$ discordou totalmente desta afirmação.

Quanto às informações explicitadas e de fácil entendimento disponibilizadas pela Treko's Mania para que o cliente consiga tomar sua decisão da compra, $77,6 \%$ dos clientes concordam totalmente com esta afirmação, e 1,3\% dos respondentes permaneceram indiferentes à este critério.

Além disso, $85,5 \%$ dos clientes concordam totalmente que sempre recebem suas mercadorias conforme estão descritas e apresentadas na fanpage, e apenas $1,3 \%$ dos respondentes discordam totalmente desta afirmação (vide Figura 5).

Figura 5 - Recebimento de mercadorias conforme descrição

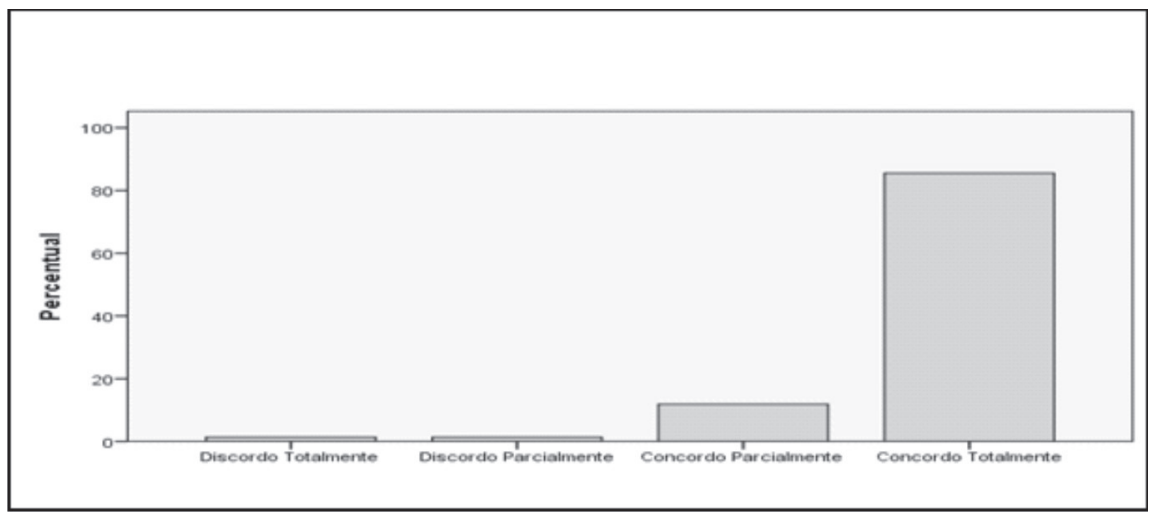

Fonte: Elaborada pelas autoras por meio do software IBM SPSS Statistics (2013).

Quando questionados sobre a variedade dos produtos da Treko's Mania, $67,1 \%$ dos respondentes concordam totalmente que atende às suas expectativas, $1,3 \%$ discorda totalmente, $1,3 \%$ discorda parcialmente e $1,3 \%$ se manteve indiferente quanto a esse critério (vide Figura 6). 
Figura 6 - Variedade de produtos

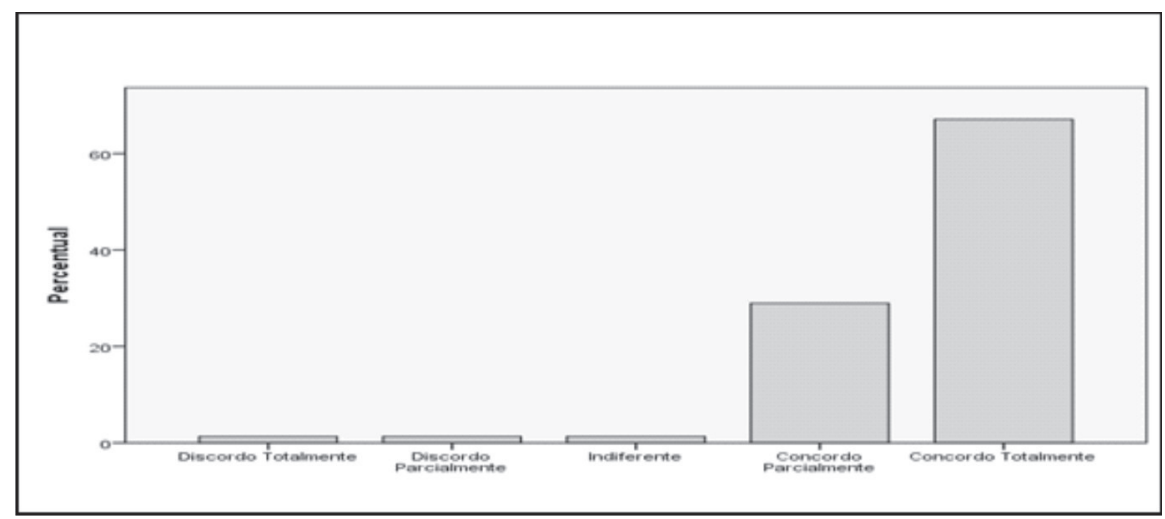

Fonte: Elaborada pelas autoras por meio do software IBM SPSS Statistics (2013).

Com relação às informações adicionais, 57,9\% dos respondentes concordam totalmente que a loja Treko's Mania oferece dicas para uso dos produtos e novidades que atendem às suas expectativas, e 2,6\% discordam parcialmente desta afirmação.

Quando questionados sobre o costume de curtir ou compartilhar produtos por acreditar que seus amigos também gostariam de receber informações, $46,1 \%$ responderam que concordam totalmente, mas $6,6 \%$ dos respondentes discordam totalmente e 6,6\% discordam parcialmente dessa afirmação.

Quando questionados sobre indicação da loja, $77,6 \%$ dos respondentes costumam indicar a loja Treko's Mania para seus familiares e amigos e apenas 1,3\% discorda totalmente (vide Figura 7). 
Figura 7 - Indicação da fanpage Treko's Mania

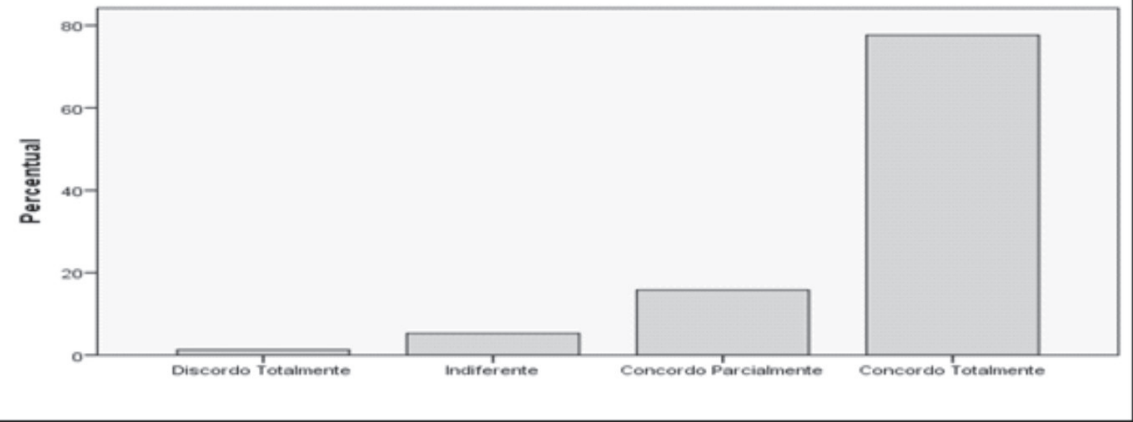

Fonte: Elaborada pelas autoras por meio do software IBM SPSS Statistics (2013).

Por conseguinte, $88,2 \%$ da amostra respondeu que concorda totalmente que a sua experiência de compra virtual da loja Treko's Mania é satisfatória, $1,3 \%$ se manteve indiferente a esse critério e não houve respostas discordando parcial ou totalmente dessa afirmação (vide Figura 8).

Figura 8 - Experiência de compra satisfatória

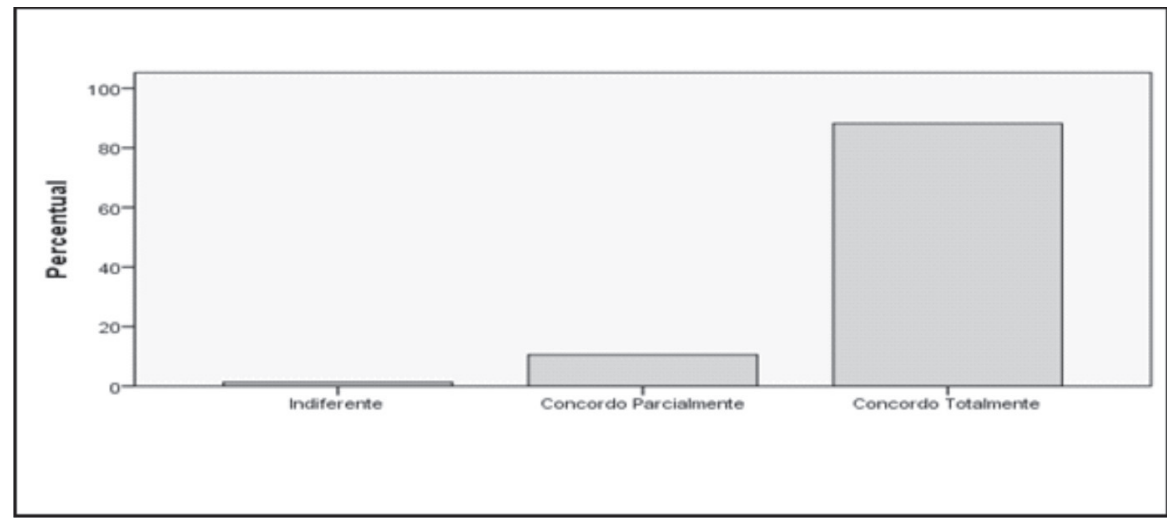

Fonte: Elaborada pelas autoras por meio do software IBM SPSS Statistics (2013).

Com a análise dos resultados obtidos, verificou-se que alguns critérios avaliados possuem maior relevância que os demais no momento 
da decisão de compra dos clientes pela fanpage Treko's Mania. A Tabela 2 apresenta os critérios avaliados de acordo com o nível de satisfação identificado:

Tabela 2 - Critérios significativos para a compra virtual na fanpage Treko's Mania

\begin{tabular}{l|l}
\hline Nível de satisfação (em \%) & Fator avaliado \\
\hline 97,4 & Prazo de entrega \\
\hline 94,7 & Relacionamento \\
\hline 93,4 & $\begin{array}{l}\text { Boa comunicação e rápida solução de } \\
\text { problemas }\end{array}$ \\
\hline 89,5 & Atendimento \\
\hline 86,8 & $\begin{array}{l}\text { Recebimento de produtos no prazo } \\
\text { fornecido }\end{array}$ \\
\hline 85,5 & $\begin{array}{l}\text { Recebimento de produtos conforme } \\
\text { descritos }\end{array}$ \\
\hline 77,6 & $\begin{array}{l}\text { Informações explicitadas, fácil } \\
\text { entendimento }\end{array}$ \\
\hline 75,0 & Qualidade dos produtos \\
\hline 67,1 & Prática de pós-vendas \\
\hline 67,1 & Variedade de produtos \\
\hline 65,8 & Condições de pagamento \\
\hline 57,9 & Dicas de produtos e novidades \\
\hline 48,7 & Preços de acordo com outras fanpages \\
\hline
\end{tabular}

Fonte: Elaborada pelas autoras (2013).

Cabe ressaltar que o questionário aplicado aos clientes da fanpage Treko's Mania era composto de afirmações com efeito positivo acerca dos critérios estudados. Nenhuma das afirmações foi respondida com percentuais significativos às opções "discordo totalmente" e "discordo parcialmente". Desse modo, pode-se afirmar que os consumidores pesquisados não apontaram dificuldades com relação à compra por meio da fanpage da loja Treko's Mania. 
Finalizada a análise das estatísticas descritivas, realizou-se a correlação simples entre todos os critérios estudados, resultando em várias correlações com níveis de significância a 0,05 e 0,01. Para manter a objetividade do estudo, optou-se por trabalhar somente as correlações significativas no nível 0,01. Santos (2007) apresenta a seguinte classificação para a correlação de acordo com os coeficientes de obtidos:

Tabela 3 - Avaliação da correlação

\begin{tabular}{l|c}
\hline Coeficiente de correlação & Correlação \\
\hline$p=1$ & Perfeita positiva \\
\hline $0,8 \leq p<1$ & Forte positiva \\
\hline $0,5 \leq p<0,8$ & Moderada positiva \\
\hline $0,1 \leq p<0,5$ & Fraca positiva \\
\hline $0<p<0,1$ & Ínfima positiva \\
\hline 0 & Nula \\
\hline$-0,1<p<0$ & Ínfima negativa \\
\hline$-0,5<p \leq-0,1$ & Fraca negativa \\
\hline$-0,8<p \leq-0,5$ & Moderada negativa \\
\hline$-1<p \leq-0,8$ & Forte negativa \\
\hline$p=-1$ & Perfeita negativa \\
\hline
\end{tabular}

Fonte: Elaborada pelas autoras com base em Santos (2007).

Optou-se por apresentar neste estudo a correlação resultante de três variáveis avaliadas: curtir e compartilhar produtos (Tabela 4), indicação fanpage (Tabela 5) e experiência de compra satisfatória (Tabela 6 ), pois se entende que estes são os resultantes que dão continuidade às atividades da fanpage Treko's Mania.

Assim sendo, analisando a correlação da variável "curtir e compartilhar produtos" identifica-se que os critérios "dicas de produtos e novidades" e "variedade de produtos" apresentam correlação moderada 
positiva, enquanto as demais variáveis analisadas possuem correlação fraca positiva, conforme Santos (2007).

Tabela 4 - Correlação curtir e compartilhar produtos

\begin{tabular}{l|l}
\hline Coeficiente de correlação & Critério correlacionado \\
\hline 0,581 & Dicas de produtos e novidades \\
\hline 0,517 & Variedade de produtos \\
\hline 0,476 & Preços de acordo com outras fanpages \\
\hline 0,473 & $\begin{array}{l}\text { Informações explicitadas, fácil } \\
\text { entendimento }\end{array}$ \\
\hline 0,472 & Indicação fanpage \\
\hline 0,384 & Prática de pós-vendas \\
\hline 0,353 & $\begin{array}{l}\text { Recebimento de produtos no prazo } \\
\text { fornecido }\end{array}$ \\
\hline 0,318 & $\begin{array}{l}\text { Recebimento de produtos conforme } \\
\text { descritos }\end{array}$ \\
\hline 0,300 & Experiência de compra satisfatória \\
\hline
\end{tabular}

Fonte: Elaborada pelas autoras com base nos dados obtidos pelo software IBM SPSS Statistics (2013)

Ao analisar a correlação entre a variável "indicação fanpage" e as demais, verificou-se que ela também possui correlação moderada positiva com o critério "dicas de produtos e novidades", e a variável "variedade de produtos" é a primeira da lista das demais variáveis que, de acordo com Santos (2007), também possuem correlação fraca positiva. 
Tabela 5 - Correlação indicação fanpage

\begin{tabular}{l|l}
\hline Coeficiente de correlação & Critério correlacionado \\
\hline 0,527 & Dicas de produtos e novidades \\
\hline 0,474 & Variedade de produtos \\
\hline 0,472 & Curtir e compartilhar produtos \\
\hline 0,412 & Atendimento \\
\hline 0,399 & $\begin{array}{l}\text { Recebimento de produtos conforme } \\
\text { descritos }\end{array}$ \\
\hline 0,373 & $\begin{array}{l}\text { Informações explicitadas, fácil } \\
\text { entendimento }\end{array}$ \\
\hline 0,366 & $\begin{array}{l}\text { Boa comunicação e rápida solução de } \\
\text { problemas }\end{array}$ \\
\hline 0,356 & $\begin{array}{l}\text { Recebimento de produtos no prazo } \\
\text { fornecido }\end{array}$ \\
\hline 0,351 & Preços de acordo com outras fanpages \\
\hline 0,311 & Relacionamento \\
\hline 0,302 & Prática de pós-vendas \\
\hline
\end{tabular}

Fonte: Elaborada pelas autoras com base nos dados obtidos pelo software IBM SPSS Statistics (2013).

Por fim, realizou-se a correlação da variável "experiência de compra satisfatória”, a qual, de acordo com Santos (2007), apresentou correlação fraca positiva com todas as variáveis estudadas, conforme a Tabela 6. 
Tabela 6 - Correlação experiência de compra satisfatória

\begin{tabular}{l|l}
\hline Coeficiente de correlação & Critério correlacionado \\
\hline 0,481 & Recebimento de produtos no prazo fornecido \\
\hline 0,480 & Relacionamento \\
\hline 0,466 & Variedade de produtos \\
\hline 0,462 & Condições de pagamento \\
\hline 0,453 & $\begin{array}{l}\text { Recebimento de produtos conforme } \\
\text { descritos }\end{array}$ \\
\hline 0,448 & Dicas de produtos e novidades \\
\hline 0,408 & $\begin{array}{l}\text { Boa comunicação e rápida solução de } \\
\text { problemas }\end{array}$ \\
\hline 0,399 & Atendimento \\
\hline 0,399 & Qualidade \\
\hline 0,398 & Informações explicitadas, fácil entendimento \\
\hline 0,341 & Prática de pós-vendas \\
\hline 0,300 & Curtir ou compartilhar produtos \\
\hline
\end{tabular}

Fonte: Elaborada pelas autoras com base nos dados obtidos pelo software IBM SPSS Statistics (2013).

\section{Considerações finais}

Com o desenvolvimento da metodologia proposta, foi possível cumprir com o objetivo geral e os específicos da investigação. Assim, o perfil dos consumidores que realizam compras virtuais por meio da fanpage Treko's Mania são, em sua maioria, mulheres, de 21 a 30 anos, residentes em Bento Gonçalves, com a mesma probabilidade de estar em um relacionamento sério ou solteiras. O nível de escolaridade que prevalece entre os consumidores estudados foi o ensino superior incompleto, apresentando trabalho remunerado e com renda familiar mensal entre $R \$ 3.500,00$ e $R \$ 4.200,00$. 
As vantagens percebidas pelos consumidores referentes à compra por meio da fanpage da loja Treko's Mania que foram identificadas neste estudo são: prazo de entrega satisfatório; bom relacionamento com o cliente, mesmo sendo via internet; boa comunicação com o vendedor e solução rápida de problemas, quando os mesmos ocorrem; bom atendimento e recebimento de produtos dentro do prazo estipulado no momento da compra.

Também foi possível identificar, por meio da análise e interpretação dos resultados, que os critérios apontados anteriormente resultam em uma maioria de clientes que curte e compartilha produtos da fanpage Treko's Mania (46,1\%) e indica a loja virtual $(77,6 \%)$. Consequentemente, identificou-se uma amostra com $88,2 \%$ dos respondentes afirmando que sua a experiência de compra com a empresa pesquisada foi satisfatória.

De acordo com o que foi exposto na análise e interpretação de resultados, os consumidores pesquisados não apontaram dificuldades com relação à compra por meio da Fanpage da loja Treko's Mania

Este estudo teve como objetivo geral identificar os fatores determinantes na decisão de compra dos consumidores virtuais da loja Treko's Mania. Com a aplicação da correlação simples entre as variáveis estudadas, verificou-se a relação existente entre os critérios que apresentaram maior relevância para os consumidores. Identificouse que as variáveis "dicas de produtos e novidades" e variável "variedade de produtos" possuem relação significativa com os critérios "curtir e compartilhar produtos" e "indicação fanpage", apresentando grande importância para a decisão de compra do consumidor. No momento da realização da correlação da variável "experiência de compra satisfatória”, constatou-se que os seguintes critérios influenciam diretamente esta variável: recebimento de produtos no prazo fornecido, bom relacionamento, variedade de produtos, condições de pagamento e recebimento dos produtos conforme descritos.

A importância desta investigação foi entender o comportamento dos consumidores da loja Treko's Mania. As contribuições deste estudo 
foram coletar dados, que poderão ser transformados em informações, dessa forma, pode ser considerado como um feedback dos clientes desta empresa, uma vez que a gerência poderá transformar esses dados em informações, a fim de melhorar o relacionamento com o seu públicoalvo, podendo ampliar ainda mais o número de novos compradores, bem como os consumidores satisfeitos.

Sugere-se, para pesquisas futuras, a investigação dos principais critérios identificados como responsáveis pela decisão de compra neste estudo, em outro segmento, buscando averiguar qual a real importância destes critérios para o consumo virtual nas redes sociais.

\section{Referências}

ACQUISTI, A.; GROSS, R. Imagined communities: awareness, information sharing, and privacy on the Facebook. Lecture Notes in Computer Science Band. Heidelberg, Germany, v. 4258, p.36-58, jun. 2006.

ANANDARAJAN, M.; THOMPSON, T.; SIMMERS, C. The internet and workplace transformation: advances in Management Information Systems, Armonk, NY: M.E. Sharpe, v.7, p.63-79, nov. 2006.

BAUMAN, Z. Vida para consumo. Rio de Janeiro: Jorge Zahar, 2008.

BESANKO, D.; DRANOVE, D.; SHANDLEY, M.; SCHAEFER, S. A economia da estratégia. 5. ed. Porto Alegre: Bookman, 2012.

BRAMBILLA, F. R. Customer relationship management (CRM): modelagem por fatores organizacionais e tecnológicos. Global Manager, [S.I.], v.8, n.14, p.107-123, jun. 2008.

BRAMBILLA, F. R. Marketing de relacionamento no contexto dos serviços de uma academia de ginástica. Global Manager, Caxias do Sul, v.9, n.16, p.107-123, jun. 2009. 
CAPRA, F. As conexões ocultas: ciência para uma vida sustentável. São Paulo: Cultrix, 2002.

CASTELLS, M. A sociedade em rede. São Paulo: Paz e Terra, 1999. CHURCHILL JÚNIOR, G. A.; PETER, J. P. Marketing: criando valor para os clientes. Tradução Cecília C. Bartalotti e Cid Knipel Moreira. 2. ed. São Paulo: Saraiva, 2007.

CORTIMIGLIA, M. N.; GHEZZI, A.; RENGA, F. Social applications: revenue models, delivery channels, and critical success factors - An exploratory study and evidence from the spanish-speaking market. Journal of theoretical and applied electronic commerce research, Talca, Chile, v.6, n.2, p.1-15, ago, 2011.

COSTA, L. et al. (Coord.). Redes: uma introdução às dinâmicas da conectividade e da auto-organização. Brasília: WWF-Brasil, 2003.

DAMBRÓS, J.; REIS, C. A marca nas redes sociais: uma proposta de gestão colaborativa. In: CONGRESSO BRASILEIRO DE CIÊNCIAS DA COMUNICAÇÃO, 31., 2008, Natal. Anais... Natal: Intercom, 2008. p. $1-15$

DEARSTYNE, B. W. Blogs, mashups, and wikis: Oh my! Information Management Journal, [S.I.], v. 41, n. 4, p.24-33, jul./aug. 2007.

ENGEL, J. F.; BLACKWELL, R. D.; MINARDI, P. W. Comportamento do consumidor. São Paulo: Pioneira Thomson Learning, 2005.

GRÖNROOS, C. From marketing mix to relationship marketing: towards a paradigm shift in marketing. Management Decision, [S.I.], V.. 32, 2, p. 4-20, 1994.

HAWKINS, D. I.; MOTHERSBAUGH, D. L.; BEST, T. J. Comportamento do consumidor: construindo a estratégia de marketing. Tradução Cláudia Mello Belhassof. 10. ed. Rio de Janeiro: Elsevier, 2007.

HUANG, C. D.; BEHARA, R. S. Outcome-driven experiential learning with web 2.0. Journal of Information Systems Education, Dearborn, MI, v. 18, n.3, p.329-336, Fall 2007. 
KOTLER, P. Administração de marketing. 12. ed. São Paulo: Pearson Prentice Hall, 2006.

LIPOVETSKY, G. A felicidade paradoxal: ensaio dobre a sociedade de hiperconsumo. Lisboa: Edições 70, 2007.

MALHOTRA, N. K. Pesquisa de marketing: foco na decisão. 3.ed. São Paulo: Pearson, 2010.

MARTELETO, R. M. Análise de redes sociais: aplicação nos estudos de transferência da informação. Ciência da Informação, Brasília, v. 30, n. 1, p.71-81, jan/abr 2001.

OVASKA, S.; LEINO, J. A survey on web 2.0. University of Tampere/ Department of Computer Sciences, Tampere, Finlândia, 2008. p.78..

PARVATIYAR, A.; SHETH, J. N. The domain and conceptual foundations of relationship marketing. In: SHETH, J. N.; PARVATIYAR, A. (eds.). Handbook of relationship marketing. Thousand Oaks: Sage Publications, 2000. cap. 1, p.3-38.

RECUERO, R. Redes sociais na internet. Porto Alegre: Sulina, 2009.

SANTOS, C. Estatística descritiva: manual de autoaprendizagem. Lisboa, Edições Silabo, 2007.

SCHULTZ, D. E. Social call. Marketing Management, [S.I], v.16, n. 4, p.9-11, 2007.

SHETH, J. N.; MITTAL, B.; NEWMAN, B. I. Comportamento do cliente: indo além do comportamento do consumidor. São Paulo: Atlas, 2001.

SODRÉ, M. Antropológica do espelho: uma teoria da comunicação linear e em rede. Petrópolis: Vozes, 2002.

SOLOMON, M. R. O comportamento do consumidor: comprando, possuindo e sendo. Porto Alegre: Bookman, 2008.

XAVIER, S. S. Comunidades virtuais: a importância da interação no aspecto da relação de consumo no ciberespaço.2012. 124 p. Dissertação 
Daniele Nespolo, Deise Taiana de Ávila Dias, Paula Patrícia Ganzer, Cristine Hermann Nodari, Milene Vieira Figueira, Maria Emilia Camargo

(mestrado em Administração) - Universidade do Grande Rio Professor José de Souza Herdy, Escola de Ciências Sociais Aplicadas, Rio de Janeiro, 2012.

Artigo recebido em: 08/04/2015

Aprovado em: 29/06/2015 